\title{
Cultural Barriers Toward Women and Youth Entry to Apiculture Production in Maara Sub-County, Kenya
}

\author{
R. Gikunda ${ }^{1}$, D. Ooga ${ }^{2}$, I. Okiamba ${ }^{3}$, S. Anyuor ${ }^{4}$
}

\begin{abstract}
The study adds to extension education knowledge by revealing cultural barriers inhibiting the uptake of apiculture enterprises among women and youths. Data were gathered through a structured interview schedule from 23 smallholder farmers selected through purposive sampling based on gender and age. The study revealed that women and youths' participation in apiculture was hindered by cultural restrictions such as taboos, inheritance, traditions, and attitudes. The taboos inhibiting women from engaging in apicultural production were forbidding them from climbing trees, sitting beehives in apiaries, and honey harvesting. Traditions such as the belief that apiculture is meant for elderly men discouraged youths and women entrance to the industry. Only interested and older sons from the farm families could inherit apiaries. A majority of female and young farmers did not participate in apiculture due to the negative attitude they had toward the enterprise. Apprenticeship was the main channel of equipping farmers with apicultural knowledge, and skills. A few farmers also acquired knowledge through formal schooling, personal experiences, and social gathering. Cultural restrictions need to be eased to attract women and young farmers to apiculture production.

Extension education could enhance the adoption of the enterprise.
\end{abstract}

\section{Keywords}

Apprenticeship, culture, extension education, indigenous knowledge

1. Raphael Mwiti Gikunda, Lecturer, Chuka University, Box 109-60400, Chuka, Kenya, rgikunda@chuka.ac.ke,

(iD) https://orcid.org/0000--0000-0000-0000

2. Dennis Mongáre Ooga, Doctoral Student, Chuka University, Box 109-60400, Chuka, Kenya, dennisooga2013@gmail.com,

(iD) https://orcid.org/0000-0001-9204-143X

3. Irene Nyanchoka Okiamba, Masters Student, Chuka University, Box 109-60400, Chuka, Kenya, ironyanchoka@gmail.com,

(iD) https://orcid.org/0000-0003-1755-4870

4. Samantha Anyuor, Graduate Assistant, Chuka University, Box 109-60400, Chuka, Kenya, anyuorsamantha@gmail.com,

iD https://orcid.org/0000-0002-9289-5977 


\section{Introduction and Problem Statement}

The apicultural subsector is rapidly growing as a result of the rising beehive nutraceutical products in local, regional, and international markets (Zoccali et al., 2017). Apiculture production involves the management of domesticated and wild honeybees for the production of honey, wax, propolis, royal jelly, and venom (Chemwok et al., 2019). Global honey production is estimated to be more than 1.4 million tonnes annually (Karpati et al., 2009). The European Union (EU) produces about 22\% of the world's production of honey; and is the second-largest producer after China (European Commission, 2020). Ethiopia is the leading producer of honey and beeswax in Africa (Frikru, 2015). Other African countries that produce substantial amounts of honey include South Africa, Zambia, Egypt, and Guinea (African Union [AU], 2019).

Apiculture is a male-dominated industry in Kenya largely because of cultural norms, the nature of management, and attitudes toward bees (Heckle et al., 2018; Mburu, 2015). As noted by Caroll and Kinsella (2013), although most parts of Kenya are suitable for apiculture production, the potential has not been fully tapped. This is due to numerous impediments, including bee ill health; inadequate supportive policies, technical advice, and marketing structures (AU, 2019); recurrent drought, deforestation (Wambua et al., 2016), and stress arising from wind, livestock, wildlife, and vandals among other challenges (Honey Bee Health Coalition, 2019). Culture has also been cited as the main hindrance to women and youth engagement in apicultural activities (Mwakatobe, Ntalwila, Kohi, Kipemba, \& Mrisha, 2016). However, little empirical data exists on cultural barriers that prevents women and young farmers from participating in the industry, particularly in high potential areas such as Maara Sub-county.

\section{Theoretical and Conceptual Framework}

We theorized that culture is an essential element in the adoption of apicultural practices. Culture is the way of life of the people (Sibani, 2018); a component of the society that embraces a range of elements, including language, economy, religion, customs, traditions, values, attitudes, education, and manners, among others (Trompenaars \& Hampden-Turner, 1997). Customs, taboos, traditions, and inheritance are cultural elements that have been thought to be a deterrent to women and youth entry to apiculture production, as illustrated in Figure 1. Although a majority of beekeepers are young people in countries such as India (Verma et al., 2018), Kenyan cultural norms make it difficult for the youth to venture into the industry.

The existence of customary inheritance practices in most communities in Kenya that favours males over females prevents women from participating in agricultural activities such as bee farming (Mwakatobe et al., 2016). In most cases, indigenous apicultural knowledge and hives are passed on to adult sons by the fathers at old age. In many cultures, women have been viewed as not suitable for physically demanding roles such as harvesting and placing log hives in tall trees. Climbing trees and handling bees are regarded as taboos in most Kenyan sub-cultures (Anoliefo et al., 2015). 


\section{Figure 1}

\section{Conceptual Framework}

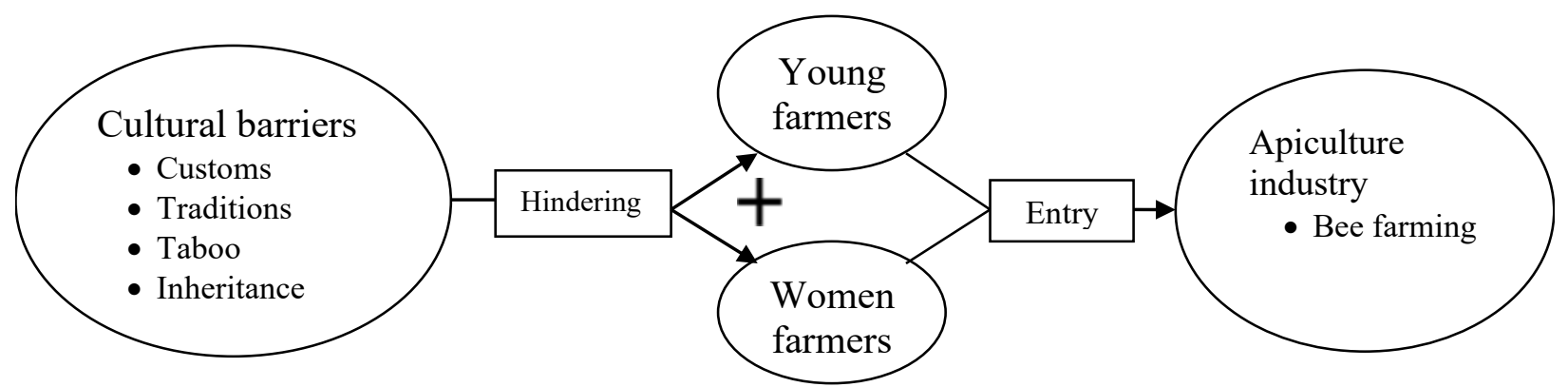

\section{Purpose}

The study was undertaken to generate information that would broaden the understanding of the factors that dissuaded women and young farmers from participating in apiculture production in Maara Sub-county of Kenya.

Two research objectives guided the study:

1. Identify cultural barriers preventing women and youth from participating in apiculture production;

2. Describe ways by which farmers acquired knowledge and skills regarding apiculture

\section{Methods}

The research was conducted in May 2020 at Maara Sub-county to document the cultural impediments to youth and women's entrance to apicultural production. Maara Sub-county is known for traditional apiculture production, although immense opportunities exist for the growth of the industry following the planned construction of a honey refinery. The area is endowed with a variety of rangelands and vegetation cover that favors apicultural activities (Tharaka Nithi County Government, 2018). The study sample was comprised of 23 smallholder farmers, where five were youths, 17 were men, and six were women. The sample was considered adequate as recommended by Creswell (2012), although Glaser and Strauss (1967) observed that the appropriateness of qualitative sample sizes is dependent on data saturation. The selection of the study site and participants was made purposively based on their gender and age. The selection was made with the help of a graduate assistant at Chuka University who had previously undertaken his masters' degree project in the target area. It is essential to disclose the researchers' roles, experiences, and biases in a qualitative study (Minus et al., 2021). Therefore, the research was undertaken by a graduate assistant at Chuka University with close supervision by the principal researcher (Faculty). The other researchers were a faculty and a graduate assistant at the university. 


\section{Data Collection and Analysis}

Primary data were collected from the respondents through the use of an interview schedule and observation. Mobile telephones were utilized to record data. The interviews were guided by a schedule that was comprised of five key questions. The questions addressed cultural factors hindering youth and women entrance to apiculture production. The study involved traditional and modern beekeepers as well as males and females to maximize the diversity of information and improve transferability of the study's results. Data were triangulated by corroborating information from the three categories of respondents' namely household heads, youth, and women.

A comprehensive description of the data collection, analysis procedures, and context within which the study was conducted ensured dependability and confirmability of the study. In addition, member checking was undertaken to double check the accuracy of the collected data. The one-to-one interviews took place at participants' farms to allow for observation of apicultural practices (Ryan, Coughlan, \& Cronin, 2009). The instrument for data collection was comprised of five open-ended questions addressing cultural barriers to women and youth participation, and the acquisition of apicultural indigenous knowledge (IDK). Audio recordings were transcribed and then data were subjected to open coding to identify the themes (Creswell, 2012). Prior to interpretation, patterns and relationships between themes were identified.

\section{Findings}

On data analysis, four themes emerged; cultural barriers (CB), acquisition of knowledge (AK), enterprise inheritance (EI), and apicultural production systems (APS).

\section{Cultural Barriers Impeding Youth and Women Entrance in Apiculture Production}

The study's first objective sought to describe the cultural barriers hindering youth and women from participating in apiculture production. The results indicated that taboos, inheritance practices, traditions, and attitudes denied women and youths a chance to participate in apiculture production.

\section{Taboos}

It was difficult for women to participate in apicultural activities due to the taboos associated with the practices. A majority of the respondents stated that it was taboo for a woman to climb a tree and an abominable act to handle bees. A claim was put forth by one of the senior male beekeepers who stated: "According to Ameru culture, women are not allowed to climb on trees, and so they cannot place hives on trees." A majority of farmers in the area practiced traditional bee farming involving log-hives that are placed on tall trees, out of reach of women apiarist. This makes it difficult for women to perform such activities as sitting beehives on trees and honey harvesting. A study conducted by Mburu et al. (2015) in Kitui, Kenya also indicated that women's participation in apiary activities faced cultural constraints such as taboos. However, the execution of apicultural activities is becoming easier with the introduction of box hives that 
are not necessary placed in tall trees in addition to other modern technologies (Heckle et al., 2018).

The results further indicated that youths and women were not allowed to handle bees due to their engagement in sexual activities. It was unacceptable to even the senior beekeepers to sleep with their wives while undertaking apiculture management practices such as honey harvesting and placement of hives in an apiary. This was reported by a respondent who stated that the "Ameru customs stipulated that a beekeeper would not 'sleep' with his wife prior to sitting a beehive in an apiary and since youths could not wait for months without making love with their wives, they would not practice beekeeping." Traditional apiculture production was a male domain as it involved the rearing of African bees (Apis millifera), which are known to be very aggressive, and thus, could not be managed by women. Certain apiculture practices were meant for men as dictated by the customs, time, and circumstance of execution. This emerged from a respondent who pointed out that "some apicultural activities such as honey harvesting were undertaken at night by men in their birthday suit [nude]." This is a clear indication that traditional apiary was a no-go-zone for women and even young people hence discouraging them from participating. The findings corroborated those of the previous studies (Chemwok et al., 2019; Ogaba \& Akongo, 2001).

\section{Traditions}

One of the senior beekeepers reported that "old men do not allow women and sons to own beehives because they believe that beehives belong to men only." "Moreover, women are considered as being incapable of beekeeping." This claim emerged from a majority of the respondents, with one of the male beekeepers stating that "women cannot climb trees" and others indicating that "women do not know how to attract bees so as to get them into a beehive." Even though research has shown that beekeeping is a less land-demanding enterprise (King, 2013), a majority of the youths and women do not own land due to cultural restrictions (FAO, 2017). As such, they would not engage in deciding the kind of agricultural activities to be practiced in their households. Our results showed that "women and youth lack space for the location of an apiary." The area's customs restrict women's land inheritance and would only allow male children to acquire land as soon as they become adults. The lack of access to basic production resources among women and youths threatened their entrance to apiculture.

Owing to the fact that most farmers in the area reared an aggressive species of bees, it was only reasonable for them to harvest honey at night, among other apicultural practices, so as to manage bee stings. It is for this reason that one of the respondents noted that bees and honey handling were done at night by senior men. "Traditionally, it was only men who were allowed to do beekeeping, and most apiary activities were conducted at night, and men would go out in 'birthday suit.' Women and children were not allowed to participate." This has been a tradition in many communities in Kenya and is practiced even today (Chemwok et al., 2019).

The community, similar to many other African communities, has well-defined gender roles (Davis \& Negash, 2007). Women are culturally expected to perform household chores and leave hard farm roles to their husbands. Apiculture production is one of those enterprises designated 
for men, as reported by one of the respondents. "According to Ameru culture, women were not allowed to participate in beekeeping. They were required to perform such duties as cooking food, porridge, tilling land, and taking care of homes. Apiary management practices were regarded as men's activities." The perception is corroborated by a finding by Miriti et al. (2019) that bee farming enterprises have been dominated by elderly men over decades. However, with the changes being witnessed worldwide geared toward women's empowerment, women are gradually participating in modern apiculture, which has eased beekeeping management due to the associated technologies (Mburu et al., 2015).

\section{Attitudes}

A majority of the respondents stated that bee phobia is a major setback to women's participation in bee farming, as pointed out by one of the women farmers that "women fear bee sting." It also emerged from one respondent that "women believed that apicultural enterprise is meant for men" because "women cannot climb on trees to harvest honey." Women's and youths' participation was also challenged by the declining security in the area. One of the respondents noted that "some people steal honey from beehives especially if the apiary is sited far away from the farmer's residence hence, a disincentive to beekeeping." Many of the senior men in the community were able to secure beehives as opposed to women and youth. To many women, apiculture production was a challenging enterprise due to the associated practices such as the construction of beehives. "Beekeeping involves hard work, especially when sculpturing traditional hives," as pointed out by a young farmer. Another farmer cited a lack of interest among women and young farmers, stating that "women and youths were not interested in beekeeping." This contradicts an observation made by Mburu et al. (2015), who found that women were interested in the production and sale of apicultural products, a situation that may have been due to the adoption of modern apicultural practices and cultural dilution. The two factors have resulted in a gradual rise in female participation in apiary activities as aided by the modernization of the industry, according to Mburu et al. (2015).

A majority of the youths do not value apiculture similar to other agricultural enterprises, as reported by a senior beekeeper who stated that "youths view beekeeping as a trivial job." A claim substantiated by Mungai and Ogot (2012), who observed that the youths' social backgrounds, which is influenced their cultural practices and beliefs, drove their attitudes toward the enterprise. Most of the senior farmers in the area kept bees for cultural uses and not as a business enterprise. Honey harvested out of the traditional apiculture was mainly used for paying dowry during marriages and brewing traditional beer. This dilutes the value of the enterprise and drives the youths away from the industry. The result is in line with the finding of Gangwar and Kameswari (2016) that a positive attitude towards agricultural enterprises is key to participation. A respondent revealed that "youths do not participate in beekeeping because it is tiresome in sculpturing hives, and they prefer white-collar jobs. They prefer new technology which has held them up like "prisoners. Therefore, they lack knowledge on beekeeping." Before the introduction of the box hives (modern hives), nearly every beekeeper was using the log hives, which not so many young farmers knew how to construct. Hence, a deterrence to many young men and women who may have wanted to engage in bee farming. 


\section{Inheritance Practices}

The results indicated that most hives had been inherited by men who showed interest in apiculture and whose commitment had impressed elderly males in their community. This was explained by a young respondent that most beekeepers particularly, men do not consider women to be beekeepers or to own any beehive, and a good man will identify his son as the one who will inherit beehives; send him to harvest honey on father's behalf when the father is no longer active in beekeeping activities. Old men do not allow women or younger sons to own any beehive because they believe that beehives belonged to old men only. The argument was emphasized by another respondent who stated that "over generations, women and youth were not allowed to participate in beekeeping. It was mainly undertaken by old men." It is clear from the results that women and youths could not inherit apiaries in most households hence preventing them from engaging in apicultural activities. This may have accounted for the negative attitude the groups had toward the enterprise.

Prior to the apiary inheritance, the inheritee would be equipped with the necessary skills and knowledge needed for bee management. It also emerged that young people were not allowed to handle honey as described by a respondent who indicated that "youths were not allowed to take honey that was prepared through traditional methods, they could start fights because it was believed that the honey is dangerous especially to youths." The fact that young people were not permitted to handle honey likely discouraged them from venturing into apiculture production. In many communities in Kenya, beekeeping is an enterprise that is mainly passed on to sons by their fathers at old age (Caroll \& Kinsella, 2013).

\section{Acquisition of Knowledge and Skills for Apicultural Production}

Objective two sought to describe ways through which beekeepers acquired knowledge and skills for beekeeping. It was reported that apicultural knowledge and skills were mainly acquired through modes of informal and formal learning.

\section{Informal Learning}

The informal modes of knowledge acquisition included apprenticeship, social gatherings, and the internet. Among the informal modes learning by practice and observation was the most commonly utilized mode of learning.

Apprenticeship. The results indicated that a majority of the beekeepers in the area acquired apicultural skills and knowledge through observations. The inheritees could accompany the senior men during visits to the apiaries and observe the apicultural practices before succeeding them (Adams, 2018). Many of the beekeepers acquired the skill from their fathers while others inherited apicultural knowledge from their grandparents, as explained by two respondents: "I learnt beekeeping skills through accompanying father in apiculture production, had taste of honey which is sweet and encouraged me to start beekeeping." "I learnt beekeeping skills from our grandfather, accompanied grandfather in setting hives on trees and harvesting of honey." To many farmers in the Maara community, apiculture production is an enterprise that is passed on from generation to generation by the male family members. 
Further, the acquisition of apicultural knowledge was entirely a family affair involving either members of the nuclear or extended families. Among the skills and knowledge acquired through apprenticeship were siting an apiary, attracting bees to the beehives, feeding bees, honey harvesting, and constructing hives. This implied that many of the beekeepers were utilizing indigenous knowledge to sustain the traditionally managed apiaries. This suggests the need for extension education to promote the uptake of modern technologies that could boost the productivity of the apiaries. The findings corroborate what was observed by Heckle et al. (2018), who found that apprenticeship is the main pathway for the transmission of traditional apicultural knowledge and skills.

Social Gathering and the Internet. Apicultural knowledge and skills were also acquired through other informal modes, including personal experiences, the internet, and social interactions. Among the informal modes was interaction within informal social groups, as suggested by a respondent who stated: "I acquired beekeeping knowledge from a certain social group. The knowledge covered attracting bees to hives, harvesting of honey, and the importance of nectar in apiculture production." A social group can provide a platform for interactive learning among individuals, as observed by Franz et al. (2010). The results also indicated that some farmers gained apicultural knowledge through personal initiatives involving the use of the internet, as claimed by one respondent who confirmed acquiring knowledge from social media. "I learnt apiculture production on social media." It has been demonstrated through research that the internet has revolutionized the way some farmers access relevant information (Chisita, 2010). However, this mode of knowledge transmission is not common in the community owing to the fact that not so many farmers, particularly the elderly group that constitutes the majority, are well versed with using the internet.

When asked to indicate how they planned to share apicultural knowledge with other farmers, one of the respondents explained that "I will print out handouts on apiculture production and put them up at strategic locations like cyber cafes where farmers who have interest can access them and learn about apiculture." This is a clear demonstration of the level of willingness of some farmers to share apicultural knowledge with others to increase bee products including honey production in the area. Yang (2015) and Šumane et al. (2018) indicated that informal channels such as social gatherings, including social media platforms among other forums are valuable avenues that can be tapped to share knowledge. As such, they could be used to boost the dissemination of apicultural practices as supported by our results.

\section{Formal Learning}

Other than informal modes of acquiring knowledge, a few beekeepers acknowledged gaining apicultural knowledge through formal processes. A formal learning environment is characterized by learning taking place in schools or colleges (Masara, 2010). The young beekeepers who may not have had a chance to culturally inherit apiaries, acquired apicultural skills formally. One member of that group indicated: "I learnt apiculture production at high school under the agriculture subject." And another one said: "I learnt about beekeeping during my primary, secondary, and university education." This implied that much of the knowledge and skills learned through formal schooling can be applied not only in traditional agriculture but also 
in other areas such as apiculture. However, formal education may not apply to a majority of the beekeepers in the area studied due to their levels and opportunities for education. Most of the beekeepers were old men who do not have formal schooling. This perhaps, explains why traditional apiculture is predominant among farmers in Maara Sub-county. Most of beekeepers who applied formal schooling knowledge were young men and women especially those engaged in modern apiculture. This confirms the assertion that education is positively correlated with adoption of modern apicultural technologies (Bunde \& Kibet, 2016).

\section{Conclusions, Discussion, and Recommendations}

Apiculture production in the Maara community is mainly based on traditional practices founded on cultural principles. A majority of beekeepers were senior men employing inherited indigenous knowledge. However, modern beekeeping was also practiced particularly by women and young people. Traditional apiculture is primarily practiced for production of bee products and honey utilized for cultural reasons such as health, brewing traditional beer, and payment of dowries. Because plans are underway for the construction of a honey refinery, it is imperative that the community expands its production to meet the projected demand. Therefore, more women and young farmers should be encouraged to engage in the apiculture industry. A shift from traditional to modern apiculture would also help to address the expected demand. This could be achieved through a spirited effort towards the dissemination of apicultural technologies involving extension agents, farmers, and other stakeholders.

Even though there is a need exists for more farmers to participate in apiculture production, women and young farmers entrance is faces numerous cultural restrictions. The cultural barriers include taboos, traditions, attitudes, and inheritance practices regarding apiaries. Some taboos such as forbidding women to climb trees, sitting beehives in apiaries, and honey harvesting deter female farmers from participating in apiculture. Only senior farmers were allowed to inherit apiaries; young farmers, similar to women, were forbidden. Engagement in sexual activities common with young people and women is a taboo that also bars the groups' entries to beekeeping. The community's traditions dictate that only senior men can participate in apiculture. This is mainly due to the associated taboos and access to resources including land.

Moreover, in traditional apiculture, most of the practices such as honey harvesting are undertaken at night making the activities out of reach for women and young people due to the fact that apiaries are often located away from the homesteads. Owing to the fact that traditional apiculture largely involves a very aggressive bee species, women and young farmers were afraid of bee stings thus discouraging them from engaging in the enterprise. Because modern apiaries do not need to be sited far away from the homes and in tall trees as in traditional apiculture, women and young people should be encouraged to participate in modern bee farming. Modern apiculture involves easy-to-perform practices like the use of box hives that can be easily be managed by women. There is need for adjusting cultural norms and beliefs to attract women and young people in the industry. 
Based on findings, it is evident that indigenous knowledge acquired informally through apprenticeship is the main driver of apiculture production in the Maara Sub-county of Kenya. In addition to, apprenticeship, other informal modes of learning involved the transmission of apicultural knowledge and skills were social gatherings and internet primarily benefiting young men and women beekeepers. Only a few beekeepers had gained apicultural knowledge through formal schooling at primary, secondary, and/or tertiary levels. This clearly indicate the need of enhanced extension service provision especially to beekeepers. Because extension is now a devolved function in Kenya, the county extensionists should organize training programs to equip farmers in the community with relevant information that can spur the growth of the industry. Youth empowerment in the area of modern beehives construction and access to resources would also likely enhance the expansion of the enterprise in Maara.

\section{References}

Adams, E. C. (2018). How to become a beekeeper: Learning and skill in managing honeybees. Cultural Geographies, 25(1), 31-47. https://doi.org/10.1177/1474474016682345

African Union (AU). (2019). The inaugural report on the status of apiculture in Africa 2019: Opportunities and strategies for development of the sector. African Union, Inter-African Bureau for Animal Resources.

Agoba, M. R., \& Akongo, T. (2001, October 28-November 1). Gender issues in beekeeping: The Uganda case [Conference session]. APIMODIA XXXVII International Apicultural Congress (ICC), Durban, South Africa. https://www.apimondia.com/docs/congress/2001/Papers/049.pdf

Anoliefo, G. O., Nwokeji, P. A., \& Ikhajiagbe, B. (2015). Influence of traditional taboo practices on natural resource conservation in Uli, Ihiala local government area of Anambra State Nigeria; Sustainable community development. Journal of Environmental Sustainability, 4(4), 1-13. http://scholarworks.rit.edu/jes/vol4/iss4/2

Bunde, A. O., \& Kibet, K. (2016). Socio-economic factors influencing adoption of modern beekeeping technologies in Baringo County, Kenya. International Journal of Science and Research, 5(6), 960-969. http://doi.org/10.21275/v5i6.NOV164195

Caroll, T., \& Kinsella, J. (2013). Livelihood improvement and smallholder beekeeping in Kenya: Unrealised potential. Development in Practice, 23(3), 332-345. https://doi.org/10.1080/09614524.2013.781123

Chemwok, C. K., Tuitoek, D. K., \& Nganai, S. K. (2019). Factors influencing honey production in Marigat, Baringo County, Kenya. International Journal of Research and Innovation in Social Science, 3(2), 426-434. https://www.rsisinternational.org/journals/ijriss/DigitalLibrary/volume-3-issue-2/426-434.pdf 
Chisita, T. C. (2012, May 24). Knotting and networking agricultural information services through Web 2.0 to create an informed farming community: A case of Zimbabwe [Conference session]. World Library and Information Congress: 78th IFLA General Conference and Assembly, Helsinki. https://conference.ifla.org/ifla78

Creswell, J. W. (2012). Educational research: Planning, conducting, and evaluating quantitative and qualitative research (4th ed.). Pearson

Davis, K. E., \& Negash, M. (2005, October 17-21). Gender, wealth, and participation in community groups in Meru Central Distirct, Kenya. [Conference session]. International Research Workshop on 'Gender and Collective Action, Chiang Mai, Thailand.

European Commission. (2020). Honey market presentation. European Union. https://www.google.com/search?q=European+Commission.+(2020).+Honey+market+pr esentation.+European+Union\&oq=European+Commission.+(2020).+Honey+market+pres entation.+European+Union \&aqs=chrome..69i57.1771j0j15\&sourceid=chrome\&ie=UTF-8

Food and Agricultural Organization (FAO). (2017). The community land rights of the women and youth in Turkana County, Kenya [Policy brief]. http://www.fao.org/3/i7037e/i7037e.pdf

Fikru, S. (2015). Review of bee and honey production in Ethiopia. Journal of Animal Science Advances, 5(10),1413-1421. https://doi.org/10.5455/jasa.20151019083635

Franz, N., Piercy, F., Donaldson, J., \& Richard, R. (2010). How farmers learn: Implications for agricultural educators. Journal of Rural Social Sciences, 25(1), 37-59. https://egrove.olemiss.edu/jrss/vol25/iss1/4

Gangwar, R., \& Kameswari, V. L. (2016). Attitude of rural youth towards agriculture as a means of livelihood. Journal of Applied and Natural Science, 8(2), 879-882. https://doi.org/10.31018/jans.v8i2.890

Glaser, B. G., \& Strauss, A. L. (1967). The discovery of grounded theory: Strategies for qualitative research. Transaction. http://www.sxf.uevora.pt/wpcontent/uploads/2013/03/Glaser 1967.pdf

Heckle, R., Smith, P., Macdiarmid, J. I., Campell, E., \& Abbott, P. (2018). Beekeping adoption: A case study of three smallholder farming communities in Baringo County, Kenya. Journal of Agriculture and Rural Development in Tropics and Subtropics, 119(1), 1-11. http://nbn-resolving.de/urn:nbn:de:hebis:34-2018010254087

Honey Bee Health Coalition. (2019). Best management practices for hive health: A guide for beekeepers (1st ed.). https://www.nmhoney.com/nmhoney/Sub_Files/Best\%20Management\%20Practices\%2 Ofor\%20Hive\%20Health\%20A\%20Guide\%20For\%20Beekeepers.pdf 
Karpati, L., Csapo, Z., \& Vanyi Arvane, G. (2009, December 9-11). Innovation and rural development: The solution for the Hungarian beekeeping sector [Paper Presentation]. European Association of Agricultural Economists (EAAE), 113th Seminar, Belgrade, Serbia. https://doi.org/10.22004/ag.econ.57486

King, L. E. (2013). Elephants and bees: Could honey bees be effective deterrents for Asia's cropraiding elephants. Sanctuary Asia Magazine. https://elephantsandbees.com/wpcontent/uploads/2013/11/King-2013-Elephants-and-Bees-in-Asia-s.pdf

Masara, C. (2010). Learning commercial beekeeping: Two cases of social learning in southern African community natrual resources management contexts [Master's thesis, Rhodes University]. South East Academic Libraries System (SEALS) Digital Commons http://hdl.handle.net/10962/d1003547

Mburu, P. D. (2015). Mapping of the honey value chain and analysis of changes in gender roles and factors influencing women empowerment among beekeepers in Kitui county, Kenya [Doctoral dissertation, University of Nairobi]. University of Nairobi Digital Repository http://hdl.handle.net/11295/93509

Mburu, P., Affognon, H., Irungu, P., Mburu, J., \& Raina, S. (2015, July 16). Beekeeping for women empowerment: Case of commercial insect programme in Kitui County, Kenya [Paper Presentation]. International Association for Feminist Economics (IAFFE) 24th Annual Conference, Berlin, Germany. https://www.researchgate.net/profile/Peter_Mburu2/publication/283727138 Beekeepi ng for Women Empowerment Case of Commercial_Insect Programme in Kitui_Cou nty Kenya/links/5645dc8508ae9f9c13e71857.pdf

Minus , K., Woods , J., Roberts, R., English, C., \& Rodriguez , B. (2021). Empowering the caregiver network of farmers with a disability: A case study of the North Carolina AgrAbility project. Advancements in Agricultural Development, 2(1), 95-106. https://doi.org/10.37433/aad.v2i1.99

Miriti, L., Masiga, C., Wamue, N., \& Maina, I. (2019). Gender gaps in the levels of participation in improved bee keeping: Case of the Maasai community in Trans Mara, Narok County, Kenya. Journal of Livestock Policy, 1(1), 1-22. https://doi.org/10.47604/ilp.v1i1.846

Mungai, E. N., \& Ogot, M. (2012). Gender, culture and enterprenuership in Kenya. International Business Research, 5(5), 175-183. http://doi.org/10.5539/ibr.v5n5p175

Mwakatobe, A. R., Ntalwila, J. A., Kohi, E. M., Kipemba, N., \& Mrisha, C. (2016). Income generation promote the participation of youth and women in beekeeping activities in Western Tanzania. Journal of Entomology and Zoology Studies, 4(4), 718-721. https://www.entomoljournal.com/archives/2016/vol4issue4/PartJ/4-3-52-191.pdf 
Ryan, F., Coughlan, M., \& Cronin, P. (2009). Interviewing in qualitative research: The one-tointerview. International Journal of Therapy and Rehabililation, 16(6), 309-316. https://www.researchgate.net/profile/Patricia_Cronin2/publication/261471599 Intervi ewing in qualitative research/links/5767ae7508ae1658e2f76d07/Interviewing-inqualitative-research.pdf

Sibani, C. M. (2018). Impact of Western culture on traditional African society: Problems and prospects. Journal of Religion and Human Relations, 10(1), 56-72. https://www.semanticscholar.org/paper/Impact-of-Western-culture-on-traditionalAfrican-Sibani/08872c47c16631c47391f2fd40f1a25d34b4f665

Šūmane, S., Kunda, I., Knickel, K., Strauss, A., Tisenkopfs, T., Rios, I. D. I., Rivera, M., Chebach, T., \& Ashkenazy, A. (2018). Local and farmers' knowledge matters! How integrating informal and formal knowledge enhances sustainable and resilient agriculture. Journal of Rural Studies, 59, 232-241. https://doi.org/10.1016/j.jrurstud.2017.01.020

Tharaka Nithi County Government. (2018). Development Plan CIDP 2018-2022. County Government of Tharaka Nithi. http://repository.kippra.or.ke/handle/123456789/2604

Trompenaars, F., \& Hampden-Turner, C. (1993). Riding the waves of culture: Understanding cultural diversity in business (2nd ed.). Nicholas Brealey.

Verma, T. C., Meena, K. C., Aswal, S., \& Singh, D. K. (2018). Socio-personal and economic analysis of apiculture enterprise in Hadauoti region of Rajasthan. Economic Affairs, 63(1), 261-268. https://doi.org/doi:10.30954/0424-2513.2018.00150.32

Wambua, B. M., Musimba, N. K., \& Muli, E. (2016). Socioeconomic analysis of beekeeping technologies in Kenya: A case study of Kitui County. International Journal of Education and Research, 4(4), 345-354. https://www.ijern.com/journal/2016/April-2016/27.pdf

Yang, J. (2015). Recognition, validation, and accreditation of non-formal and informal learning. UNESCO Institute of Lifelong Learning. https://unesdoc.unesco.org/ark:/48223/pf0000232656.

Zoccali, P., Malacrino, A., Campolo, O., Laudani, F., Algeri, G. M., Giuntu, G., \& Palmeri, V. (2017). A novel GIS-based approach to assess beekeeping suitability of Mediterranean lands. Saudi Journal of Biological Science, 24 (5),1045-1050. http://doi.org/10.1016/j.sjbs.2017.01.062

(C) 2021 by authors. This article is an open access article distributed under the terms and conditions of the Creative Commons Attribution license (http://creativecommons.org/licenses/by/4.0/). 